\title{
Safety and Immunogenicity of a Pseudomonas aeruginosa O-Polysaccharide Toxin A Conjugate Vaccine in Humans
}

\author{
S. J. Cryz, Jr.," E. Fürer,* A. S. Cross, ${ }^{\star}$ A. Wegmann, ${ }^{\star}$ R. Germanier," and J. C. Sadoff \\ ${ }^{*}$ Swiss Serum and Vaccine Institute, 3001 Berne, Switzerland; ${ }^{*}$ Walter Reed Army Institute of Research, Washington, DC $20307-5100$
}

\begin{abstract}
Lipid A-free polysaccharide (PS) isolated from Pseudomonas aeruginosa immunotype 5 lipopolysaccharide (LPS) was covalently coupled to toxin A via reductive amination. The PS-toxin A conjugate was comprised of $29.8 \%$ PS and $70.2 \%$ toxin A, possessed a molecular weight of $>1 \times 10^{6}$, was nontoxic for animals and was nonpyrogenic for rabbits at a dose of $50 \mu \mathrm{g} / \mathrm{kg}$ body wt when administered intravenously. The conjugate evoked only mild, transient reactions upon subcutaneous administration to human volunteers. Vaccination engendered immunoglobulin G (IgG) antibody, which neutralized the cytotoxic effect of toxin $A$ and promoted the uptake and killing of $P$. aeruginosa in the presence of human polymorphonuclear leukocytes. Passively transferred IgG isolated from the serum of immunized donors was far more effective at preventing fatal $P$. aeruginosa burn wound sepsis than paired preimmunization serum. These studies establish the potential usefulness of such a PS-toxin A conjugate as a vaccine against $P$. aeruginosa.
\end{abstract}

\section{Introduction}

Gram-negative aerobic bacilli are the leading cause of fatal nosocomial infections $(1,2)$. Preeminant among these pathogens is Pseudomonas aeruginosa, whose ability to cause life-threatening infections in compromised patients is well documented $(3,4)$. The case fatality rate for $P$. aeruginosa bacteremia reported in the literature from 1951 to 1981 has remained in the range of 25 to $50 \%(4,5)$, indicating the limited impact of antibiotic therapy.

The use of immunological means as an adjunct to antimicrobial chemotherapy for the control of $P$. aeruginosa infections has recently gained much attention $(4,6)$. Human immunity to $P$. aeruginosa had been found to correlate with humoral antibody directed against serospecific epitopes expressed by LPS and against toxin $A(7,8)$. A reduction in fatalities due to $P$. aeruginosa among compromised patients has been obtained following vaccination with an LPS-based vaccine $(9,10)$. However, the high frequency of adverse reactions associated with vaccination has limited its use.

The above findings indicate that optimal protection against $P$. aeruginosa would be obtained by use of a vaccine capable of eliciting both anti-LPS and anti-toxin A antibody. We have pre-

Address reprint requests to Dr. S. J. Cryz, Jr., Swiss Serum and Vaccine Institute, P.O. Box 2707, 3001 Berne, Switzerland.

Received for publication 8 August 1986 and in revised form $25 \mathrm{Feb}$ ruary 1987.

J. Clin. Invest.

(C) The American Society for Clinical Investigation, Inc. 0021-9738/87/07/0051/06 \$2.00

Volume 80, July $1987,51-56$ viously demonstrated that serologically active nonimmunogenic $O$-polysaccharide $(O \text {-PS })^{1}$ derived from LPS could be covalently linked to toxin A, yielding a conjugate vaccine (11). This conjugate was found to be nontoxic for animals and capable of evoking both an anti-LPS and an anti-toxin A immune response. We now report on the safety and immunogenicity of an $O$-PStoxin A conjugate vaccine in humans.

\section{Methods}

Purification of antigens. LPS was purified from $P$. aeruginosa strain W18 (immunotype 5) as previously described (12). The final preparation of LPS contained $<1 \%$ (wt/wt) protein or nucleic acid (12).

PS was obtained from LPS by acid hydrolysis (11). Briefly, LPS (suspended in $1 \% \mathrm{vol} / \mathrm{vol}$ acetic acid) was heated for $90 \mathrm{~min}$ at $100^{\circ} \mathrm{C}$. After cooling, the suspension was centrifuged at $5,000 \mathrm{~g}$ for $15 \mathrm{~min}$. The lipid A-containing pellet was discarded and the supernatant extracted three times with chloroform/methanol (3:1). After concentration by rotory evaporation, the aqueous phase was passed over a $5 \times 40-\mathrm{cm}$ column of AcA34 (LBK-Produkter, Bromma, Sweden) equilibrated in distilled water. The PS fractions eluting with a relative molecular mass $\left(M_{\mathrm{r}}\right)$ $\leq 50,000$ were pooled, concentrated, and lyophilized.

Toxin A was purified from the culture supernatants of $P$. aeruginosa PA103 as previously described (13). The purity of the toxin A preparations as measured by high pressure liquid chromatography (E. I. DuPont Co., Wilmington, DE, GF-250 column) (see below) was $\geq 96 \%$. The mean lethal dose when administered intraperitoneally to $18-20 \mathrm{~g}$ female NMRI mice was between 0.1 and $0.25 \mu \mathrm{g}$ per mouse.

Synthesis of PS-toxin A conjugate. The PS-toxin A conjugate was produced essentially as described elsewhere (11). Briefly, PS was oxidized by treatment with $\mathrm{NaIO}_{4}$ at $22^{\circ} \mathrm{C}$, after which ethylene glycol was added to exhaust residual $\mathrm{NaIO}_{4}$. This procedure generated approximately seven equivalents of reducing activity. After extensive dialysis, the oxidized PS was lyophilized. Adipic acid dihydrazide (ADH) was introduced into the toxin A molecule by the use of carbodiimide $(11,14)$. Approximately $13 \mathrm{~mol}$ of ADH were incorporated into each mole of toxin A as determined by reaction with 2,4,6-trinitrobenzenesulfonic acid (TNBS) using $\mathrm{ADH}$ to generate a standard curve. Toxin A-ADH was covalently coupled to oxidized PS by mixing equal amounts at $22^{\circ} \mathrm{C}$ for $6 \mathrm{~h}$. At this time, $\mathrm{NaCNBH}_{3}$ was added to reduce Schiffs bases and the mixture stored at $22^{\circ} \mathrm{C}$ for $5 \mathrm{~d}$. The mixture was then extensively dialyzed against phosphate-buffered saline (PBS) and filtered over an AcA34 column equilibrated in PBS. The conjugate contained no detectable reactive hydrazide groups as determined by reaction with TNBS. Collected fractions were analyzed by measuring the absorbance at 220 and $280 \mathrm{~nm}$, respectively. The material that eluted in the void volume of the column $\left(M_{\mathrm{r}}>350,000\right)$ was pooled and lyophilized.

Analytical methods. The protein content of the conjugate was measured by the method of Lowry et al. (15) using toxin A as a standard. The carbohydrate content was determined by the tryptophane reaction (16) using purified $P$. aeruginosa $\mathrm{PS}$ as a standard.

1. Abbreviations used in this paper: ADH, adipic acid dihydrazide; ADPR, adenosine diphosphateribosyl; ELISA, enzyme linked immunosorbent assay; LPS, lipopolysaccharide; $O$-PS, $O$-polysaccharide from lipopolysaccharide; PBS-T; PBS containing 0.02\% Tween-20. 
Enzymatic activity assay. The adenosine diphosphateribosyl (ADPR)transferase activity of toxin A was measured as previously described after activation in the presence of urea and dithiothreitol (17). All assays were performed in duplicate. The background value (all assay reagents except toxin A protein) was subtracted to yield specific counts. The sensitivity of this assay is $<1 \mathrm{ng}$ toxin $\mathrm{A}$. To determine if the conjugate possessed residual enzymatic activity, increasing amounts of toxin A protein as conjugate ( $100 \mathrm{ng} /$ assay to $1 \mu \mathrm{g} /$ assay) were tested. A negative result was defined as follows: specific counts $<50 \%$ above background value and no evidence of an increase in specific counts with an increasing amount of conjugate protein assayed. Enzyme neutralization assays were performed as follows. To $50 \mathrm{ng}$ of toxin A in $10 \mu \mathrm{l}$ of $50 \mathrm{mM}$ Tris, $\mathrm{pH} 8$, were added $10 \mu \mathrm{l}$ of sera or IgG (see below). The mixture was placed at $37^{\circ} \mathrm{C}$ for $30 \mathrm{~min}$, after which time the assay was completed as described above.

Cytotoxicity neutralization assay. The ability of sera to neutralize the cytotoxic effect of toxin A was tested as previously described except Chinese hamster ovary cells were used in place of HEp-2 cells (11).

Mouse lethality assay. The lethal effect of toxin A or conjugate vaccine for mice was evaluated by the intraperitoneal injection of graded doses of toxin A or conjugate. Mice (female, NMRI strain, weighing 18-20 g) each received $200 \mu \mathrm{g}$ of conjugate protein, equal to 1,000 mean lethal doses of native toxin A. Mice were observed daily for $14 \mathrm{~d}$ postinjection.

Enzyme-linked immunosorbent assays (ELISA). ELISA for the quantitation of anti-toxin A and anti-LPS IgG were performed as previously described $(11,13)$. The conjugate used was peroxidase-labeled protein A produced by the method of Nakane and Kawaoi (18). Color was allowed to develop for $10 \mathrm{~min}$ after the addition of the substrate solution (11) and read at $405 \mathrm{~nm}$ on a Titertek Multiscan (Flow Laboratories, Hamden, CT).

A standard curve for the quantitation of IgG was produced as follows. Affinity purified goat anti-human IgG (Kirkegaard and Perry, Gaithersburg, MD) was diluted in PBS $(10 \mu \mathrm{g} / \mathrm{ml})$ and $200 \mu$ ladded to each well of a flat-bottomed microtiter plate. The plates were incubated for $3 \mathrm{~h}$ at $37^{\circ} \mathrm{C}$ and then stored at $4^{\circ} \mathrm{C}$ until used. After three washes with PBS containing $0.02 \%$ Tween-20 (PBS-T), $200 \mu$ l of purified human IgG (Globuman, Swiss Serum and Vaccine Institute, Berne, Switzerland) from $0.009 \mu \mathrm{g} / \mathrm{ml}$ to $10 \mu \mathrm{g} / \mathrm{ml}$ in twofold serial dilutions were added per well. The plates were then processed in the same manner as described above. When the results were plotted as the absorbance at $405 \mathrm{~nm}$ versus the $\log$ of IgG concentration, the linear portion of the curve was found between 0.03 and $0.7 \mu \mathrm{g} \mathrm{IgG/ml.} \mathrm{Human} \mathrm{IgG}$ was excluded from control wells.

Specific IgG antibody to LPS or toxin A in human serum was derived as follows. A dilution of each test serum giving an absorbance within the linear region of the standard curve was used to calculate micrograms of IgG. This value was then multiplied by the dilution factor to yield micrograms $\mathrm{IgG} / \mathrm{ml}$ of serum.

Opsonophagocytosis assay. Opsonophagocytic assays were performed as previously described (19).

Column chromatography. The conjugate vaccine was sized by gel filtration over Sephacryl S-500. The column $(1 \mathrm{~cm} \times 45 \mathrm{~cm})$ was equilibrated in PBS and calibrated with Blue Dextran 2000 and $\left[{ }^{14} \mathrm{C}\right]$ sodium acetate.

Vaccine. Conjugate-containing fractions that eluted in the void volume of an AcA34 column (see above) were pooled and the protein and carbohydrate content determined. The conjugate was diluted in an equal volume of $10 \%(\mathrm{wt} / \mathrm{vol})$ lactose. This was further diluted in $5 \%(\mathrm{wt} / \mathrm{vol})$ lactose in PBS to yield a final conjugate concentration of $100 \mu \mathrm{g} \mathrm{car}-$ bohydrate and $225 \mu \mathrm{g}$ protein $/ \mathrm{ml}$. This was passed through a $0.45-\mu \mathrm{m}$ filter under aseptic conditions. The vaccine $(1 \mathrm{ml})$ was placed in sterile glass vials and lyophilized under asceptic conditions. The vials were labeled, sealed, and stored at $4^{\circ} \mathrm{C}$.

Tests for sterility and general safety of the vaccine were performed according to requirements set forth under articles V.2.1.1 and V.2.1.5 of the European Pharmacopoeia (20). Pyrogenicity testing was performed in New Zealand white rabbits as previously described (21).

Subjects and study design. Healthy volunteers of both sexes aged
16-59 participated in the trial. The vaccine was reconstituted in sterile distilled water immediately before use. Volunteers received either 0.5 $\mathrm{ml}(162.5 \mu \mathrm{g}$ of conjugate equal to $50 \mu \mathrm{g}$ of PS) or $0.25 \mathrm{ml}(81.25 \mu \mathrm{g}$ of conjugate equal to $25 \mu \mathrm{g}$ of PS) by the subcutaneous route in the deltoid region on days 0 and 28. Adverse reactions including local pain, swelling, redness, induration, fever, chills, malaise, or headache were recorded on a control sheet for $5 \mathrm{~d}$ postimmunization.

Venous blood samples were obtained on days 0 (at the time of vaccination), 2-3, 14, 28, 30, and 42 . Aliquots of serum were frozen at $-20^{\circ} \mathrm{C}$. Serum or heparinized whole blood from each timepoint was analyzed by the Clinical Laboratory Service at the Insel Hospital, Berne, Switzerland, for hemoglobin, hematocrit, erythrocyte, leukocyte, thrombocyte, and differential leukocyte counts, creatinine, serum glutamateoxalacetate-transaminase and serum glutamate-pyruvate-transaminase.

Isolation of IgG. Two serum pools were made by combining $0.5 \mathrm{ml}$ of serum from each volunteer collected on day 0 (preimmune pool) or on day 42 (postimmune pool). IgG was obtained from each pool by published techniques (22). The purified IgG was reconstituted to the original starting volume in saline, passed through a $0.45-\mu \mathrm{m}$ filter and stored at $-20^{\circ} \mathrm{C}$. The concentration of IgG was determined by use of a Partigen test kit (Boehringer Mannheim, Mannheim, West Germany). Postimmune IgG was absorbed with the $O$-PS-toxin A conjugate as follows. To $2 \mathrm{ml}$ of IgG was added $1.25 \mathrm{mg}$ of conjugate. The mixture was incubated for $1 \mathrm{~h}$ at $37^{\circ} \mathrm{C}$. The resulting precipitate was removed by centrifugation at $12,000 \mathrm{~g}$ for $10 \mathrm{~min}$ and the final supernatant passed through a $0.4-\mu \mathrm{m}$ filter. This material was concentrated over a ym-10 filter (Amicon Corp., Danvers, MA) and applied to a Sepharose CL-4B column to separate free conjugate from IgG. The IgG fractions were collected and concentrated. This procedure was repeated once and the material filter sterilized before use.

Passive protection studies. Female NMRI mice weighing between 18 and $20 \mathrm{~g}$ were used. Each mouse received $40 \mu \mathrm{g}$ of $\mathrm{IgG}$ via the tail vein at time 0 . Approximately $24 \mathrm{~h}$ later, mice were burned and challenged with graded doses of $P$. aeruginosa strain W-18 (immunotype 5) or PA220 (immunotype 1) $(12,23)$. Groups of six mice were used. Mortality was recorded for $7 \mathrm{~d}$ post-challenge.

Statistical analysis. The mean lethal dose was calculated according to the method of Reed and Muench (24).

\section{Results}

Various characteristics of the $O$-PS-toxin A conjugate vaccine are shown in Table I. The conjugate was composed of toxin A and $O$-PS at a ratio of 2.3:1. The vaccine possessed a molecular weight of $\sim 2 \times 10^{6}$ as determined by gel filtration and was devoid of ADPR-transferase activity. The conjugate was nonpyrogenic when tested at a dose of $50 \mu \mathrm{g} / \mathrm{kg}$ and nontoxic upon intraperitoneal administration to mice and guinea pigs. To document that the vaccine was not subject to toxic reversion when exposed to physiologic temperatures, the following experiments were performed. Reconstituted vaccine was incubated at $37^{\circ} \mathrm{C}$ for $28 \mathrm{~d}$ at which time $200 \mu \mathrm{g}$ of conjugate protein (equivalent to 1,000 mean lethal doses for native toxin A protein) was injected intraperitoneally into mice. No overt signs of illness were observed and all mice survived. Similarly, there was no evidence of an increase in enzymatic activity after storage.

The above results, demonstrating the safety and stability of the conjugate vaccine, led us to evaluate its acceptability and immunogenicity in humans. Healthy adult volunteers received either $162.5 \mu \mathrm{g}$ of vaccine (equal to $50 \mu \mathrm{g}$ of $O$-PS and $112.5 \mu \mathrm{g}$ of toxin A protein) or $81.25 \mu \mathrm{g}$ of vaccine (equal to $25 \mu \mathrm{g}$ of $O$ PS and $56.25 \mu \mathrm{g}$ of toxin A protein) subcutaneously in the deltoid region. Reactions to vaccination are shown in Table II. Only a single vaccinee noted a local reaction after the first vaccination. One subject experienced malaise $24 \mathrm{~h}$ postimmunization that 
Table I. Characteristics of PS Toxin A Conjugate Vaccine

\begin{tabular}{lllll}
\hline \multicolumn{2}{l}{ Composition* } & & & \\
\hline Protein & Carbohydrate & $M_{\mathrm{r}}^{*}$ & $\begin{array}{l}\text { ADPR-transferase } \\
\text { activity }\end{array}$ & Pyrogenicity \\
\hline$\%$ & $\%$ & & & $\mu \mathrm{kg}$ \\
70.2 & 29.8 & $2 \times 10^{6}$ & ND" & 50 \\
\hline
\end{tabular}

* Values shown are on a weight basis.

‡ Determined by filtration over Sephacryl S-500.

When administered intravenously to rabbits, $50 \mu \mathrm{g}$ of vaccine per $\mathrm{kg}$ body weight evoked $<0.5^{\circ}$ increase in temperature.

"ND = nondetected.

lasted for $<24 \mathrm{~h}$. Reactions were more frequent following the booster dose of vaccine administered on day 28 . A total of six subjects (30\%) reported a local reaction, while two noted a systemic reaction (malaise and a slight headache). The majority of vaccinees who experienced a local reaction had received the higher vaccine dose. All reactions were mild, did not hinder normal functions and were spontaneously resolved within $48 \mathrm{~h}$. No significant alterations in blood chemistry or serum liver enzyme profiles were noted that could be attributed to vaccination over the 6-wk observation period.

The ability of the $O$-PS-toxin A conjugate to elicit an IgG antibody response that recognized native LPS and toxin $A$ is shown in Table III. The magnitude of the anti-LPS response was comparable at both immunizing doses with 70 to $90 \%$ of the vaccinees responding with a significant (fourfold or greater) rise in specific IgG. It should be noted that two of the three subjects, who received the $81.25-\mu \mathrm{g}$ dose and did not respond, possessed the highest levels of anti-LPS IgG in their preimmune sera $(12.1$ and $13.9 \mu \mathrm{g} / \mathrm{ml})$ seen in this study. The mean concentration of anti-LPS IgG in postimmune sera was comparable for both groups. In contrast, the immune response to the toxin A component was more vigorous in volunteers who received the higher immunizing dose. Whereas on day $42,90 \%$ of the subjects who received the $162.5-\mu \mathrm{g}$ of vaccine responded with a greater than or equal to fourfold rise in anti-toxin IgG, only $60 \%$ did so at the $81.25-\mu \mathrm{g}$ dose. Similarly, the mean concentration of anti-toxin IgG in postimmunization sera was approximately threefold higher for the group that received the 162.5- $\mu \mathrm{g}$ dose. It is interesting to note that the second dose of vaccine administered on day 28 resulted in a substantially higher seroconversion rate to toxin A. This effect is most evident in the group which received the $162.5-\mu \mathrm{g}$ dose of vaccine, where the percentage of subjects responding increased from $40 \%$ after primary immunization to $90 \%$ after the second dose of vaccine. A similar trend in the immune response to LPS was not observed. There was no detectable anti-ADH response after immunization, illustrated by the fact that postimmune sera did not bind to ADH-sensitized ELISA plates.

Next, functional activities of antibody elicited the following immunization with the conjugate vaccine were evaluated. Antibody directed against the toxin A moiety of the conjugate were able to neutralize the cytotoxic potential of purified toxin A (Table IV). The mean toxin A-neutralizing capacity in postimmune sera and the meanfold rise in specific anti-toxin A IgG were comparable at both vaccine doses, as were the number of volunteers showing a more than fourfold rise in titer. Only 4 of 20 subjects $(20 \%)$ possessed detectable levels of toxin A-neutralizing antibody in their preimmunization serum $(0.4$ to 0.8 $\mu \mathrm{g}$ of toxin A neutralized per $\mathrm{ml}$ of serum). All responded with a more than fourfold rise in neutralizing capacity after vaccination.

Vaccination with the conjugate did not evoke a significant rise in antibody capable of neutralizing the ADPR-transferase activity of toxin A. Pooled preimmune sera reduced the enzymatic activity of toxin A by an average of $15.4 \%$, whereas the level of inhibition was increased to only $32 \%$ when pooled postimmunization (day 42) sera were tested.

Antibody directed against the $O$-PS moiety of the conjugate vaccine was capable of promoting the phagocytosis and killing of an IT-5 strain of $P$. aeruginosa by human polymorphonuclear leukocytes (Table V). Both immunizing doses were found to be equally effective at engendering an opsonic antibody response. The postimmune mean titer was comparable in both groups, as were the number of individuals responding with a significant (more than fourfold) rise in titer. All but one volunteer, who received the low vaccine dose, made a significant response.

The ability of antibody evoked following immunization with the conjugate vaccine to afford protection against fatal experimental $P$. aeruginosa immunotype 5 burn wound sepsis is shown in Table VI. Compared with mice that received human albumin, both preimmune and postimmune IgG were able to increase the $\mathrm{LD}_{50}$. The level of protection was dependent upon the amount of specific antibody transferred. Therefore, while preimmune $\mathrm{IgG}$ raised the $\mathrm{LD}_{\text {so }}$ value 14 -fold over the human albumin-treated group, the administration of postimmune IgG with $\sim 10$-fold higher antibody content resulted in a further 100 -fold increase. To confirm that protection was indeed me-

Table II. Reactions Noted after Immunization with O-PS Toxin A Conjugate Vaccine

\begin{tabular}{|c|c|c|c|c|c|c|c|c|c|}
\hline \multirow[b]{2}{*}{ Immunizing dose* } & \multirow[b]{2}{*}{ Immunization $^{\ddagger}$} & \multicolumn{4}{|c|}{ Local reactions } & \multicolumn{4}{|c|}{ Systemic reactions } \\
\hline & & Pain & Swelling & Redness & Itching & Fever & Chills & Malaise & Headache \\
\hline \multicolumn{10}{|l|}{$\mu g$} \\
\hline \multirow[t]{2}{*}{81.25} & 1 & 0 & 0 & 0 & 0 & 0 & 0 & 0 & 0 \\
\hline & 2 & 1 & 0 & 0 & 0 & 0 & 0 & 2 & 2 \\
\hline \multirow[t]{2}{*}{162.5} & 1 & 1 & 0 & 0 & 0 & 0 & 0 & 1 & 0 \\
\hline & 2 & 3 & 2 & 1 & 1 & 0 & 0 & 0 & 0 \\
\hline
\end{tabular}

* Volunteers immunized with $81.25 \mu \mathrm{g}$ of conjugate received $25 \mu \mathrm{g}$ of $O$-PS and $56.25 \mu \mathrm{g}$ of toxin A protein. Volunteers immunized with 162.5 $\mu \mathrm{g}$ of conjugate received $50 \mu \mathrm{g}$ of $O$-PS and $112.5 \mu \mathrm{g}$ of toxin A protein. ${ }^{\ddagger}$ The first immunization was on day 0 and the second was on day 28 . 
Table III. IgG Response after Immunization with the O-PS Toxin A Conjugate Vaccine

\begin{tabular}{|c|c|c|c|c|c|c|}
\hline \multirow[b]{2}{*}{ Immunizing dose* } & \multirow[b]{2}{*}{ Immune response to } & \multicolumn{3}{|c|}{ Mean $\mu \mathrm{g} \operatorname{lgG} / \mathrm{ml}$ serum (range) } & \multicolumn{2}{|c|}{ Nr. $\geq$ 4-fold rise/total } \\
\hline & & Day $0^{*}$ & Day $14^{*}$ & Day $13^{*}$ & Day $14^{*}$ & Day $42^{*}$ \\
\hline \multirow[t]{2}{*}{$81.25 \mu g$} & Toxin A & $0.19(0.07-0.54)$ & $8.2(0.07-40)$ & $9.4(0.12-54)$ & $4 / 10$ & $6 / 10$ \\
\hline & LPS & $5.8(0.16-13.9)$ & $49(0.5-178)$ & $30(0.5-125)$ & $7 / 10$ & $7 / 10$ \\
\hline \multirow[t]{2}{*}{$162.5 \mu g$} & Toxin A & $1.42(0.09-12)$ & $19.4(0.1-80)$ & $29(0.2-169)$ & $4 / 10$ & $9 / 10$ \\
\hline & LPS & $1.57(0.3-3.1)$ & $30.6(1.9-160)$ & $32(2.9-160)$ & $7 / 10$ & $9 / 10$ \\
\hline
\end{tabular}

* Volunteers were immunized on day 0 and 28. Subjects vaccinated with $81.25 \mu \mathrm{g}$ of conjugate received $25 \mu \mathrm{g}$ of $O$-PS and $56.25 \mu \mathrm{g}$ of toxin A. Subjects vaccinated with $162.5 \mu \mathrm{g}$ of conjugate received $50 \mu \mathrm{g}$ of $O$-PS and $112.5 \mu \mathrm{g}$ of toxin A. ${ }^{\ddagger}$ Relative to the time of immunization (day 0 ). Indicates the number of volunteers showing a fourfold or greater rise in specific IgG compared to preimmunization levels.

diated by anti-conjugate antibody, postimmune IgG was absorbed with the conjugate vaccine. This procedure, which reduced the levels of antitoxin A and anti-LPS antibody to slightly below those for preimmune IgG, resulted in a corresponding loss in protective capacity. It is interesting to note that submicrogram amounts of specific antibody could confer an extremely high degree of protection in this model system.

To determine the relative protective roles of antitoxin A versus anti-LPS antibody in this model system, the following experiment was performed. Groups of mice received either preimmune or postimmune IgG before burning and challenge with a toxin A-producing strain of a heterologous LPS immunotype (immunotype 1). The $\mathrm{LD}_{\mathbf{5 0}}$ value for both groups was identical $\left(2 \times 10^{3}\right)$ indicating that the protection noted above was mediated primarily by anti-LPS antibody. These findings are in agreement with previously published studies showing that antitoxin A antibody is poorly protective in this model system against highly virulent challenge strains (13).

\section{Discussion}

The need for immunological agents to aid in the control of $P$. aeruginosa infections is documented by the fact that mortality rates for nosocomial bacteremic episodes have remained essentially unchanged for the past three decades $(4,5)$. Immunoprophylactic or immunotherapeutic intervention is complicated by the fact that various patient populations are at risk to acquiring

Table IV. Ability of the O-PS Toxin A Conjugate to Elicit Toxin A-Neutralizing Antibody

\begin{tabular}{|c|c|c|c|}
\hline \multirow[b]{2}{*}{ Immunizing dose* } & \multicolumn{2}{|c|}{$\begin{array}{l}\text { Mean } \mu \mathrm{g} \text { of toxin A neutralized } \\
\text { per } \mathrm{ml} \text { of serum }\end{array}$} & \multirow[b]{2}{*}{ Nr. $\geq 4$-fold rise/total } \\
\hline & Preimmune ${ }^{\ddagger}$ & Postimmune & \\
\hline $81.25 \mu g$ & 0.12 & 2.64 & $6 / 10$ \\
\hline $162.5 \mu g$ & 0.16 & 2.9 & $6 / 10$ \\
\hline
\end{tabular}

* Volunteers were immunized on day 0 and 28. Subjects vaccinated with $81.25 \mu \mathrm{g}$ of conjugate received $25 \mu \mathrm{g}$ of O-PS and $56.25 \mu \mathrm{g}$ of toxin A. Subjects vaccinated with $162.5 \mu \mathrm{g}$ of conjugate received $50 \mu \mathrm{g}$ of O-PS and $112.5 \mu \mathrm{g}$ of toxin A.

${ }^{\ddagger}$ Preimmune $=$ prior to vaccination (day 0 ).

Postimmune $=2 \mathrm{wk}$ after receiving the second immunization (day 42). a life-threatening $P$. aeruginosa infection $(4,6)$. Therefore, the mode in which a $P$. aeruginosa vaccine is employed would depend upon the immune status of the individual. Active vaccination is a feasible approach in certain high-risk groups, such as in burned or surgical patients who have been shown to mount a good humoral immune response to parenterally administered $P$. aeruginosa antigens $(10,25,26)$. Immunosuppressed patients, on the other hand, would not be expected to benefit greatly from immunization due to their depressed capacity to mount an antibody response $(9,27,28)$. In such cases, a hyperimmune gammaglobulin for intravenous use produced from the plasma of immunized donors would be the most logical approach.

Promising, but inconclusive results from clinical trials using a polyvalent LPS vaccine suggest that an immunological approach against $P$. aeruginosa infections is possible (10). Supporting this hypothesis is the finding that elevated levels of antibody to LPS and toxin A have been found to correlate with survival from $P$. aeruginosa bacteremia and may act in an independent and additive manner $(7,8)$. This would indicate that optimal protection against $P$. aeruginosa would be obtained by use of a vaccine capable of eliciting both anti-LPS and anti-toxin $A$ antibody. We have, therefore, selected toxin $A$ to serve as the carrier protein for nonimmunogenic serospecific $O$-PS in the construction of a conjugate to meet these requirements.

The $O$-PS-toxin A conjugate vaccine presently described was found to be safe when parenterally administered to healthy adult volunteers. No systemic reactions of consequence (fever, chills, etc.) were noted and local reactions were infrequent and mild in nature. No significant abnormalities in blood chemistry or

Table V. Opsonic Antibody Response after Vaccination with the O-PS Toxin A Conjugate Vaccine

\begin{tabular}{llll}
\hline & \multicolumn{2}{c}{ Mean opsonic titer (range) } & $\begin{array}{l}\text { Nr. } 24 \text { 4fold } \\
\text { rise/total }\end{array}$ \\
\cline { 2 - 4 } Immunizing dose* & Preimmune $^{*}$ & Postimmune $^{*}$ & $8 / 10$ \\
$81.25 \mu g$ & $40(10-160)$ & $596(40-2,560)$ & $10 / 10$ \\
$162.5 \mu g$ & $58(10-160)$ & $528(160-1,260)$ &
\end{tabular}

* Volunteers were immunized on days 0 and 28. Subjects vaccinated with $81.25 \mu \mathrm{g}$ of conjugate received $25 \mu \mathrm{g}$ of O-PS and $56.25 \mu \mathrm{g}$ of toxin A. Subjects vaccinated with $162.5 \mu \mathrm{g}$ of conjugate received $50 \mu \mathrm{g}$ of O-PS and $112.5 \mu \mathrm{g}$ of toxin A.

${ }^{\ddagger}$ Preimmune, prior to vaccination.

${ }^{8}$ Postimmune, $2 \mathrm{wk}$ after receiving the second immunization as in Table IV (day 42). 
Table VI. Capacity of Passively Transferred Human IgG Preparations to Prevent Fatal P. aeruginosa Burn Wound Sepsis

\begin{tabular}{lccc}
\hline & \multicolumn{2}{l}{$\begin{array}{l}\text { ng IgG transferred/ } \\
\text { Mouse }\end{array}$} & \\
\cline { 2 - 3 } Material transferred * & Toxin A & LPS & Mean lethal dose \\
\hline Human albumin & - & - & $1.4 \times 10^{3}$ \\
Preimmune IgG' & 22.4 & 32 & $2 \times 10^{4}$ \\
Postimmune IgG" & 250 & 376 & $2 \times 10^{6}$ \\
Postimmune IgG absorbed" & 8 & 15 & $2 \times 10^{3}$ \\
& & & \\
\hline
\end{tabular}

* Mice each received $0.2 \mathrm{ml}$ of $\mathrm{IgG}$ preparation or $0.2 \mathrm{ml}$ of human serum albumin ( $160 \mu \mathrm{g} /$ mouse) intravenously $24 \mathrm{~h}$ before challenge with $P$. aeruginosa.

${ }^{\ddagger}$ Indicated the amount (ng) of specific antitoxin IgG and anti-LPS IgG each mouse received.

${ }^{8}$ Prepared from equal aliquots of serum taken from all volunteers before immunization.

" Prepared from equal aliquots of serum taken from all volunteers 42 d postimmunization.

' Postimmune IgG was twice absorbed with immunotype 5 O-PS toxin A conjugate prior to administration.

serum liver enzyme levels were seen following vaccination. This is particularly important because the liver is the target organ for toxin A $(29,30)$. It would appear that the covalent coupling of $\mathrm{ADH}$ to toxin A, which destroys the enzymatic activity of the molecule by which toxicity is mediated, results in a detoxified protein not subject to in vivo reversion.

Immunization with the conjugate engendered both anti-toxin IgG and anti-LPS IgG antibody. The mean level of anti-toxin A IgG induced by immunization $(9.4$ and $29.0 \mu \mathrm{g} / \mathrm{ml}$ at the 25 and 50- $\mu \mathrm{g}$ doses, respectively) were comparable to those measured in patients who survived a bacteremic episode with a toxin A-producing strain of $P$. aeruginosa $(25.8 \mu \mathrm{g} / \mathrm{ml})(7)$. Similarly, the concentration of anti-LPS found in the serum of vaccinated individuals ( 30 and $32 \mu \mathrm{g} / \mathrm{ml}$ at the $25-$ and $50-\mu \mathrm{g}$ doses, respectively) was also comparable to levels obtained by survivors of $P$. aeruginosa bacteremia $(12.8 \mu \mathrm{g} / \mathrm{ml})(31)$. Of perhaps greater significance was the finding that both anti-LPS and antitoxic antibody possessed the desired functional attributes. Therefore, anti-toxin $A$ antibody was capable of neutralizing the cytotoxic activity of toxin A while anti-LPS antibody was opsonic. Furthermore, human antibody directed against the conjugate was highly protective against fatal $P$. aeruginosa infection when evaluated in a murine burn sepsis model.

The $O$-PS-toxin A conjugate vaccine described herein possesses those characteristics desired of a $P$. aeruginosa vaccine; it was safe upon parenteral administration to humans, stable, and capable of evoking high levels of antibody to both toxin A and LPS, which exhibited the necessary functional attributes essential for protection against infection. Since the highest survival rate following $P$. aeruginosa bacteremia was found among patients with elevated levels of antibody to both toxin A and LPS (8), the currently described vaccine may prove to be more efficacious than other $P$. aeruginos $a$ candidate vaccines capable of engendering an immune response to only one $P$. aeruginosa antigen $(6,16,32,33)$.

Prior seroepidemiological surveys have noted that several serotypes of $P$. aeruginos $a$ can be responsible for life-threatening infections $(6,32)$. Therefore, any vaccine using serospecific antigen would have to be multivalent. It is presently envisioned that such a polyvalent conjugate vaccine would be composed of the appropriate serotypes of $O$-PS coupled to toxin A. However, due to the considerable heterogeneity in the monosaccharide composition of $O$-PS between serotypes $(34,35)$, it remains to be seen if the conjugation strategy currently used can be applied with comparable results to other relevant $O$-PS antigens.

\section{Acknowledgments}

Excellent technical assistance was provided by J. Schlup, S. Balmer, D. Pavlovic; and S. Futrovsky. We thank Dr. M. Maag for providing fermenter cultures, Dr. S. Varallyay for safety, pyrogenicity, and sterility testing, and L. Cryz for preparation of the manuscript.

\section{References}

1. McGowan, J. E., Jr. 1985. Changing etiology of nosocomial bacteremia and fungemia and other hospital acquired infections. Rev. Infect. Dis. (Suppl). 7:S357-S379.

2. Gross, P. A., H. C. Mew, P. Aswapokee, C. van Antwerpen, and N. Aswapokee. 1980. Deaths from nosocomial infections: experience in a university hospital and a community hospital. Am. J. Med. 68:219223.

3. Cross, A., J. R. Allen, J. Burke, G. Ducel, A. Harris, J. John, D. Johnson, M. Lew, B. MacMillan, P. Meers, R. Skalova, R. Wenzel, and J. Tenney. 1983. Nosocomial infections due to Pseudomonas aeruginosa: review of recent trends. Rev. Infect. Dis. 5(Suppl.):S837-S845.

4. Bodey, G. P., R. Bolivar, V. Fainstein, and L. Jadeja. 1983. Infections caused by Pseudomonas aeruginosa. Rev. Infect. Dis. 5:279313.

5. Bryan, C. S., K. L. Reynolds, and E. R. Brenner. 1983. Analysis of 1,186 episodes of gram-negative bacteremia in non-university hospitals: the effects of antimicrobial therapy. Rev. Infect. Dis. 5:629-638.

6. Cryz, S. J., Jr. 1984. Pseudomonas aeruginosa infections. In Bacterial Vaccines. R. Germanier, editor. Academic Press, Inc., Orlando, FL. 317-351.

7. Cross, A. S., J. C. Sadoff, B. H. Iglewski, and P. A. Sokol. 1980. Evidence for the role of toxin $A$ in the pathogenesis of infection with Pseudomonas aeruginosa in humans. J. Infect. Dis. 142:538-546.

8. Pollack, M., and L. Young. 1979. Protective activity of antibodies to exotoxin A and lipopolysaccharides at the onset of Pseudomonas aeruginosa septicemia in man. J. Clin. Invest. 63:276-286.

9. Young, L. S., R. D. Meyer, and D. Armstrong. 1973. Pseudomonas aeruginosa vaccine in cancer patients. Ann. Intern. Med. 79:518-527.

10. Alexander, T. W., and M. Fisher. 1974. Immunization against Pseudomonas in infection after thermal injury. J. Infect. Dis. 130(Suppl.): S152-S158.

11. Cryz, S. J., Jr., E. Fürer, J. C. Sadoff, and R. Germanier. 1986. Pseudomonas aeruginosa immunotype 5 polysaccharide-toxin A conjugate vaccine. Infect. Immun. 52:161-165.

12. Cryz, S. J., Jr., T. L. Pitt, E. Fürer, and R. Germanier. 1984. Role of lipopolysaccharide in virulence of Pseudomonas aeruginosa. Infect. Immun. 44:508-513.

13. Cryz, S. J., Jr., E. Fürer, and R. Germanier. 1983. Protection against Pseudomonas aeruginosa infection in a murine burn wound sepsis model by passive transfer of antitoxin $A$, antielastase and anti-lipopolysaccharide. Infect. Immun. 39:1072-1079.

14. Schneerson, R., O. Barrera, A. Sutton, and J. B. Robbins. 1980. Preparation, characterization and immunogenicity of Haemophilus influenzae type b polysaccharide protein conjugates. J. Exp. Med. 152: 361-376.

15. Lowry, O. H., N. J. Rosenbrough, A. L. Farr, and R. J. Randall. 1951. Protein measurement with the Folin phenol reagent. J. Biol. Chem. 193:265-275. 
16. Williams, P. 1968. Carbohydrate analysis. Methods Immunol. Immunochem. 2:287.

17. Iglewski, B. H., and J. C. Sadoff. 1979. Toxin inhibitors of protein synthesis: production, purification and assay of Pseudomonas aeruginosa toxin A. Methods Enzymol. 60:780-793.

18. Nakane, P. K., and R. Kawaoi. 1974. Peroxidase-labeled antibody: a new method of conjugation. J. Histochem. Cytochem. 22:1084-1091.

19. Sadoff, J. C., H. Sidberry, J. Schilhab, D. Hirschfeld, and A. Cross. 1980. Opsonic and bacterial-binding activity of immunoglobulin preparations. In Immunoglobulins: Characteristics and Uses of Intravenous Preparations. B. M. Alving and J. S. Finlayson, editors. Government Printing Office, Department of Health, Education and Welfare Publication; (FDA)-80-9005. p. 63-71.

20. European Pharmacopoeia. 1980. 2nd ed. Sainte-Ruffine, France: Maisonneuve.

21. Cryz, S. J., Jr., E. Fürer, and R. Germanier. 1985. Purification and vaccine potential of Klebsiella capsular polysaccharides. Infect. Immun. 50:225-230.

22. Novotny, A. 1969. Basic Exercises in Immunochemistry. SpringerVerlag, New York. 3-6.

23. Stieritz, D. D., and I. A. Holder. 1975. Experimental studies of the pathogenesis of infections due to Pseudomonas aeruginosa: description of a burned mouse model. J. Infect. Dis. 131:688-691.

24. Reed, L. J., and H. Muench. 1938. A simple method of estimating fifty percent endpoints. Am. J. Hyg. 27:493-497.

25. Jones, R. S. 1979. Antibody response of burned patients immunized with a polyvalent Pseudomonas vaccine. J. Hyg. 82:453-462.

26. Polk, H. C., Jr., S. Border, and J. A. Aldrete. 1973. Prevention of Pseudomonas respiratory infection in a surgical intensive care unit. Ann. Surg. 177:607-615.
27. Haghbin, M., D. Armstrong, and M. L. Murphy. 1973. Controlled prospective trial of Pseudomonas aeruginosa vaccine in children with acute leukemia. Cancer. 32:761-766.

28. Pennington, J. E., H. Y. Reynolds, R. E. Wood, R. A. Robinson, and A. S. Levine. 1975. Use of a Pseudomonas aeruginosa vaccine in patients with acute leukemia and cystic fibrosis. Am. J. Med. 58:629636.

29. Woods, D. E., and B. H. Iglewski. 1983. Toxins of Pseudomonas aeruginosa: new perspectives. Rev. Infect. Dis. 5(Suppl.):S715-S722.

30. Young, L. S. 1972. Human immunity to Pseudomonas aeruginosa. II. Relationship between heat-stable opsonins and type-specific lipopolysaccharides. J. Infect. Dis. 126:277-287.

31. Pier, G. B., and S. E. Bennett. 1986. Structural analysis and immunogenicity of Pseudomonas aeruginosa immunotype 2 high molecular weight polysaccharide. J. Clin. Invest. 77:491-495.

32. Pier, G. B., and D. M. Thomas. 1982. Lipopolysaccharide and high-molecular-weight polysaccharide serotypes of Pseudomonas aeruginosa. J. Infect. Dis. 145:217-223.

33. Lydick, E., A. A. McLean, A. F. Woodhour, and L. T. Callahan, III. 1985. Response of adult volunteers to a Pseudomonas aeruginosa exotoxoid-A vaccine. J. Infect. Dis. 151:375.

34. Knirel, Y. A., A. S. Shashkov, B. A. Dmitrier, and N. K. Kochetor. 1984. Structural studies of the Pseudomonas aeruginosa immunotype 1 antigen, containing the new sugar constituents 2-acetamido-2-deoxy-Dgalacturonic acid and 2-deoxy-2-formamido-D-galacturonic acid. Carbohydrate Res. 133:C12-C14.

35. Horten, D., and G. Rodemeyer. 1977. Analytical characterization of lipopolysaccharide antigens from seven strains of Pseudomonas aeruginosa. Carbohydrate Res. 55:35-47. 